\title{
Modulation of the isoform expression of Cyr61 and integrin-av in human microvascular endothelial cells
}

\author{
Sarah Gauck, Heinz-Peter Schultheiss, Ursula Rauch and Andreas Eisenreich* \\ *Correspondence: andreas.eisenreich@charite.de \\ Charité - Universitätsmedizin Berlin, Campus Benjamin Franklin, Centrum für Herz- und Kreislaufmedizin, 12200 Berlin, Germany.
}

\begin{abstract}
Background: Endothelial cells regulate angiogenesis and vessel wall homeostasis via bioactive factors, such as cysteine-rich 61 (Cyr61) and Integrin- $\mathrm{v}\left(\operatorname{Itg}_{\alpha} \mathrm{v}\right)$. Pre-mRNA splicing leads to the expression of two Cyr61 mRNA splice variants (Cyr61_IS, Cyr61_IR) and three $\operatorname{Itg}_{\alpha} v$ isoforms $\left(\operatorname{Itg}_{\alpha} \mathrm{v} \_1,2,3\right)$. Splicing is important for the functional multiplicity and is regulated via the serine/arginine-rich (SR) protein kinases, Cdc2-like kinases (Clk) and DNA topoisomerase I (DNA topo I). Here, we study the impact of these SR protein kinases on the Cyr61 and $\operatorname{Itg}_{\alpha} \mathrm{v}$ isoform expression as well as on the endothelial cell proliferation and pro-angiogenic properties of human microvascular endothelial cells (HMEC-1).

Methods: We assessed the expression of Cyr61 and $\operatorname{Itg}_{\alpha} \mathrm{v}$ isoforms via RT-PCR and Western blotting. Cellular functions were determined by adequate assays (MTT proliferation assay, in vitro angiogenesis assay).

$\underline{\text { Results: }}$ We found Clks as well as DNA topo I to modulate the differential isoform expression of Cyr61 and Itg $\operatorname{lat}_{\alpha}$, the protein expression and secretion in resting as well as in TNF- $\alpha$-stimulated HMEC-1. Moreover, these processes affected the endothelial cell proliferation and pro-angiogenic tube formation by HMEC-1. Finally, treatment of cells with recombinant Cyr61_IS or siRNA-mediated silencing of Cyr61_IS and Cyr61_IR also modulated these functions.

Conclusions: This study indicates DNA topo I and Clks to regulate the differential isoform expression Cyr61 and Itg $\mathrm{v}_{\alpha}$ and to affect regenerative endothelial functions under normal and pro-inflammatory conditions.
\end{abstract}

Keywords: Endothelial cells, inflammation, cytokines, kinase

\section{Introduction}

Endothelial cells are crucial regulators of important vascular functions, such as vascularisation and vessel wall homeostasis [1-3]. Endothelial cell functions, such as angiogenesis and cell proliferation are crucial for the regenerative formation of new blood vessels [4]. Both processes are controlled by bioactive molecules, such as cysteine-rich 61 (Cyr61; [4]) and the corresponding integrin receptors [5], such as Integrin- $v$ $\left(\mid \operatorname{tg}_{a} v ;[6]\right) . C y r 61$ is expressed in several cell types and tissues including endothelial cells, monocytes and the heart $[4,6,7]$. Due to alternative splicing, Cyr61 is expressed in two mRNA splice variants $[7,8]$. Constitutive splicing of the primary transcript leads to the skipping of all intronic sequences including intron 3 and, subsequently, to the generation of the functional Cyr61_IS protein [8]. Due to alternative splicing, intron 3 can be retained in the mature mRNA splice variant Cyr61_intron retention (IR). This splice variant is assumed to be not protein-coding due to early translation stop signals within the alternative mRNA sequence [8]. It was shown that the cellular functions of Cyr61, such as angiogenesis and cell migration can be regulated by modulations of the Cyr61_IS/Cyr61_IR ratio [8].

$\operatorname{Itg}_{a} v$ was shown to be an important receptor for Cyr61, mediating its cellular functions in several cell types, including endothelial cells $[6,9]$. Itg $g_{a} v$ is also expressed in several mRNA splice variants, Itg $v_{a} v_{-} 1$ (accession number: NM_002210.3), Itg ${ }_{a} \vee \_2$ (accession number: NM_001144999.1) and $\operatorname{ltg}_{a} v_{-} 3$ (accession number: NM_001145000.1). The specific physiologic roles of these isoforms are unknown. However, the $\operatorname{ltg}_{a} v$ protein is known to be involved in several cellular function including cell proliferation and angiogenesis [6,9].

Alternative splicing of primary transcripts or pre-messenger RNAs (pre-mRNAs) plays an important role in regulating gene expression and functional multiplicity [10-12]. The four Cdc2like kinases (Clk) 1-4 and the DNA topoisomerase I (DNA topo I) were shown to regulate constitutive as well as alternative splicing processes [10-15]. The exact mechanism of DNA topo I and Clk-mediated splicing regulation was described in detail by others $[\mathbf{1 0 , 1 2 ]}$.

It is unknown whether Clks and DNA topo I are involved in the control of pre-mRNA splicing of Cyr61 and its receptor $\operatorname{ltg}_{a} v$ in endothelial cells. Moreover, the impact of the modulated isoform expression on endothelial cell function is also not known. Therefore, in this study we characterized the impact of Clks and DNA topo I on the isoform expression of Cyr61 and $\operatorname{ltg}_{a} v$ and the functional consequences of these regulatory processes on endothelial cell proliferation and pro-angiogenic tube formation by human microvascular endothelial cells (HMEC-1).

\section{Methods \\ Cell culture}

Human microvascular endothelial cells (HMEC-1; PromoCell $\mathrm{GmbH}$, Heidelberg, Germany) were cultured in Endothelial 
Gauck et al. Cardiovascular System 2013,

Cell growth medium (containing 10\% FCS, PromoCell GmbH, Heidelberg, Germany). For starvation and performance of functional assays and inhibition experiments, Endothelial Cell growth medium (containing 1\% FCS, PromoCell $\mathrm{GmbH}$, Heidelberg, Germany) was used. SiRNA-mediated inhibition was done by transfection with Cyr61_IR(5'-AGACUUCUCAGAGGCAUACCCCC-3') or Cyr61_IS-specific (5'-AUUCCAAAAACAGGGAGCCCCC-3') siRNAs (200 nM) or non-sense control (IBONI ${ }^{\circledR}$ siRNA Negative Control-N1, \# K-00101-0001-N1) siRNA (200 nM; Riboxx GmbH, Radebeul, Germany). Transfection was performed using Lipofectamine ${ }^{\mathrm{TM}}$ 2000 (Invitrogen $\mathrm{GmbH}$, Karlsruhe, Germany). The transfection efficiency was approximately $50 \%$. The inhibitory effect of specific siRNAs was validated on mRNA level. The knockdown efficiency was 35\% for siCyr61_IS and $60 \%$ for siCyr61_IR). For stimulation experiments recombinant ( $r$ )Cyr61_IR (PeproTech GmbH, Hamburg, Germany ) was used. For inhibition experiments, HMEC-1 were pre-treated with TG003 (Clk inhibitor, $10 \mu \mathrm{M}$; Calbiochem, Darmstadt, Germany [33]) or camptothecin (DNA topo I inhibitor, $100 \mathrm{nM}$; Calbiochem, Darmstadt, Germany [34]) for $1 \mathrm{~h}$. After that, the HMEC-1 were stimulated with $10 \mathrm{ng} / \mathrm{mL}$ TNF-a (Sigma-Aldrich Chemie $\mathrm{GmbH}$, Munich, Germany). Analyses of mRNA expression were done after $2 \mathrm{~h}$ and protein expression was determined after $24 \mathrm{~h}$. Positive controls were stimulated with TNF-a only and negative controls were not treated.

\section{Western blotting}

Western blot analysis of samples from HMEC-1 cell lysates was performed as described previously [13]. For analysis of Cyr61_IS in the supernatant of HMEC- 1 the medium was collected after $24 \mathrm{~h}$, respectively. Soluble proteins in the supernatant were precipitated by treatment with $10 \%$ trichloroacetic acid (TCA) overnight at $4^{\circ} \mathrm{C}$. Since there is no established protein loading control for secreted proteins, equal protein loading was certified by determining the amount of total protein via a BCA assay. For Western blot experiments, $20 \mu \mathrm{g}$ of whole protein were used. For detection, specific antibodies against GAPDH (Calbiochem, Darmstadt, Germany), Itg $v$ (Abcam, Cambridge, UK), and Cyr61_IS (a kind gift from Lester F. Lau, University of Illinois, Chicago, IL, USA) were used.

\section{qRT-PCR}

Total RNA was reverse transcribed using AMV (Roche Diagnostics $\mathrm{GmbH}$, Mannheim, Germany), and cDNAs encoding Cyr61_IS, Cyr61_IR, Itg $v_{a} \_1, \mid \operatorname{tg}_{a} v \_2, \operatorname{Itg}_{a} v \_3$, and GAPDH were amplified as previously described [13]. The used primers were:

Cyr61_IS_for: 5'-TCCTCTGTGTCCCCAAGAAC-3'; Cyr61_IS_rev: 5'-TTCAGGCTGCTGTACACTGG-3'; Itg $v_{a}$ _1/3_for: 5'-GGCTAGCCGAGAAGAG AGC3'; Itg ${ }_{a} v_{-}$1/3_rev: 5'-ATCTCCGACAGCCACAGAAT-3'; Itg $v_{a}{ }_{2}$ 2_for: 5'-CССТССАTC ТСТTCATTCCA-3'; Itg ${ }_{a} v_{2}$ 2_rev: 5'-ATCTCCGACAGCCACAGAAT-3';
GAPDH_for: 5'-GAGTCAACGGATTTGGTCGT-3'; GAPDH_rev: 5'GACAAGCTT CCCGTTCTCAG3' (Ocimum Biosolutions Ltd., Hyderabad, India). Quantification was performed by Gel-Pro Analyzer ${ }^{\mathrm{TM}}$ software version 4.0.00.001 (Media Cybernetics, Bethesda, MD, USA).

\section{Tube formation assay}

The in vitro Angiogenesis Assay Kit from Millipore (Billerica, MA, USA) was used following the manufacturer's protocol. $7.5 \times 10^{3}$ HMEC- 1 cells per well were seeded on $50 \mu \mathrm{L}$ of the ECMatrix $^{\mathrm{TM}}$ in 96 -well plates in $200 \mu \mathrm{L}$ endothelial cell growth medium with or without pharmacologic inhibitors of Clks and DNA topo I, siRNAs against Cyr61_IS and Cyr61_IS, or recombinant Cyr61_IS protein and incubated for $5 \mathrm{~h}$ at $37^{\circ} \mathrm{C}$ in a humidified air incubator with $5 \% \mathrm{CO}_{2}$. Thereafter, the number of ring structures formed by HMEC-1 was determined and compared to controls. Tube formation was analysed using a Leica DMIL light microscope (Leica, Wetzlar, Germany).

\section{MTT assay}

HMEC-1 cell proliferation was measured by MTT assay. Here, $2.5 \times 10^{4}$ cells per well were seeded in 96-well plates. HMEC1 were incubated for $48 \mathrm{~h}$ with or without pharmacologic inhibitors, siRNAs or recombinant proteins, respectively, at $37^{\circ} \mathrm{C}$ in humidified air with $5 \% \mathrm{CO}_{2}$. Thereafter, $25 \mu \mathrm{L}$ of MTT $(5 \mathrm{mg} / \mathrm{mL})$ were added to each well and incubated for further $3 \mathrm{~h}$. Then, the reaction was stopped by adding solubilization solution and the samples were incubated for another hour at $37^{\circ} \mathrm{C}$. Finally, the concentration of the generated formazan product was determined at $570 \mathrm{~nm}$ in a VERSAmax Microplate Reader (Molecular Devices $\mathrm{GmbH}$, Ismaning, Germany). Cell number was determined using a standard curve.

\section{Statistical analysis}

All data were expressed as mean \pm SEM. Data were analyzed by Student's $t$-test or one-way ANOVA as appropriate. A probability value $\leq 0.05$ was regarded as significant.

\section{Results \\ Modulation of the isoform expression of Cyr61 in HMEC-1}

Since modulating the isoform expression of Cyr61 was recently shown to influence cellular function of cancer cells [8], we were interested in the impact of SR protein kinases on the isoform expression pattern of Cyr61. Moreover, inflammation is known to modulate important endothelial cell functions [3], such as cell proliferation and angiogenesis. We studied HMEC1 under normal as well as under inflammatory conditions.

Stimulation of HMEC- 1 for $2 \mathrm{~h}$ with $10 \mathrm{ng} / \mathrm{mL}$ TNF-a induced the mRNA expression of the protein-coding Cyr61_IS isoform (Figure 1A). Pre-treatment of cells with $100 \mathrm{nM}$ of the DNA topo I inhibitor camptothecin significantly reduced the mRNA level of Cyr61_IS in resting as well as in TNF-a-stimulated cells. Inhibition of Clks via $10 \mu \mathrm{M} \mathrm{TG003}$ also reduced the 


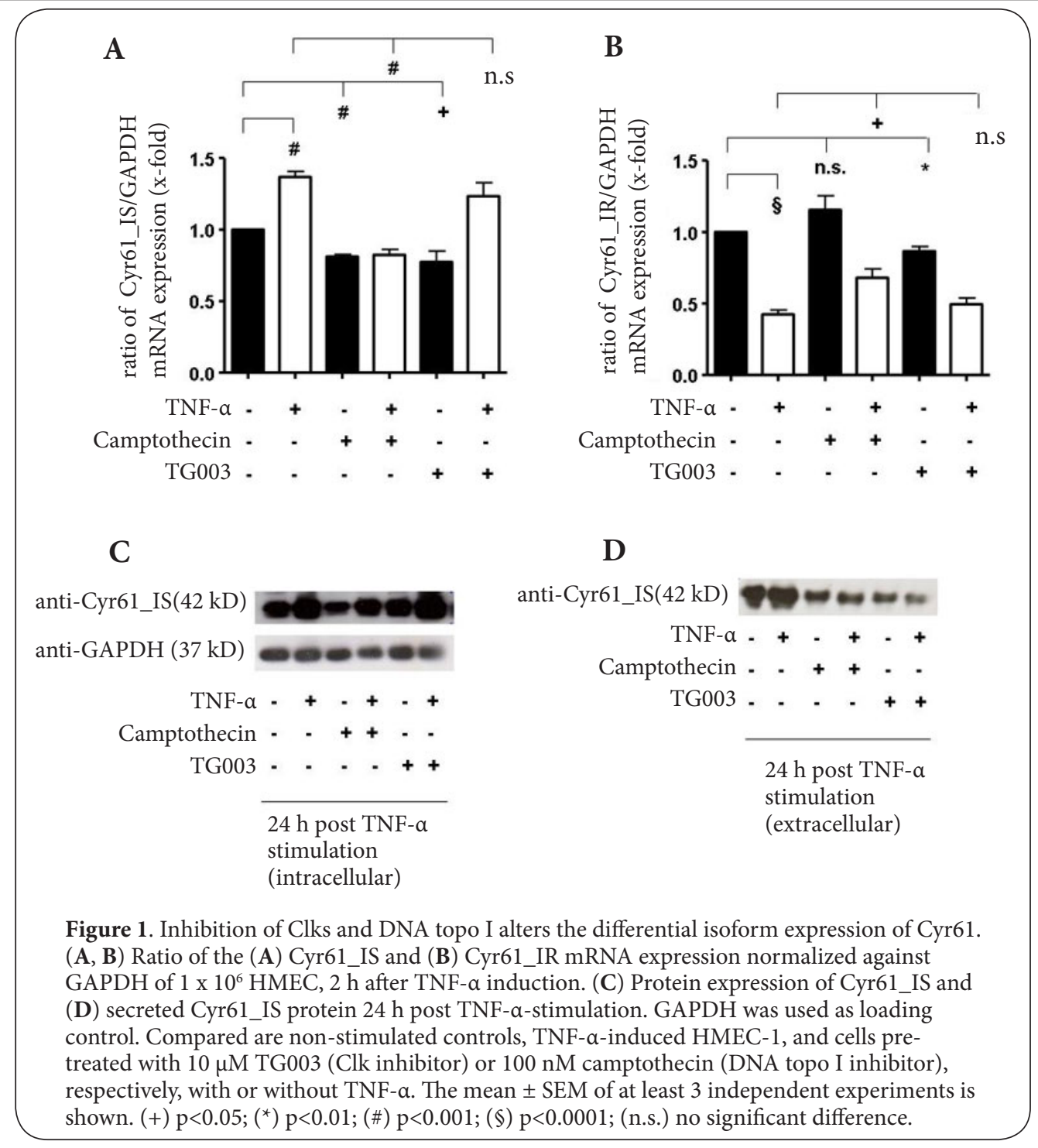

Cyr61_IS expression in unstimulated HMEC-1, whereas, the Cyr61_IS was not significantly changed in TNF-a-treated cells (Figure 1A). In contrast to Cyr61_IS, stimulation of HMEC-1 with TNF-a reduced the mRNA expression of the non-coding Cyr61_IR splice variant (Figure 1B). Inhibition of the DNA topo I had no significant impact on the Cyr61_IR mRNA level in resting cells, whereas, the expression was significantly decreased in TNF-a-induced cells. In contrast to DNA topo I blocking, inhibition of Clks by TG003 reduced the expression of Cyr61_IR in non-stimulated cells, whereas, there was no significant effect in TNF-a-treated HMEC-1 (Figure 1B).

Since there are only Cyr61_IS-detecting antibodies available, we analysed the effect of DNA topo I or Clk inhibition on the Cyr61_IS protein expression and secretion in the next step. As found on mRNA level, stimulation of HMEC-1 for $24 \mathrm{~h}$ with TNF-a increased the protein expression of Cyr61_IS (Figure 1C). Inhibition of DNA topo I reduced Cyr61_IS in resting as well as in TNF-a-induced cells, compared to the corresponding controls. In contrast to the mRNA level, the inhibition of Clks by TG003 had no impact on the Cyr61_IS protein expression in resting HMEC-1, whereas, the level of Cyr61_IS was slightly elevated in TNF-a-stimulated cells (Figure 1C). The protein secretion was also modulated $24 \mathrm{~h}$ post induction (Figure 1D). As found on protein expression level, stimulation with TNF-a increased the amount of Cyr61_IS protein in the supernatant of HMEC-1. Inhibition of the DNA topo I by camptothecin also reduced the level of Cyr61_IS secreted by resting as well as by TNF-a-induced HMEC-1. In contrast to protein expression, secretion of the functional Cyr61_IS isoform was reduced in resting as well as in TNF-a-stimulated cells pre-treated with the Clk inhibitor TG003 (Figure 1D).

\section{The impact of Clk and DNA topo I on the $\operatorname{Itg}_{\alpha} v$ isoform expression in HMEC-1}

Integrins, such as $\operatorname{ltg}_{\alpha} \mathrm{v}$ are important receptors for Cyr61mediated signaling [6]. Therefore, we characterized the 

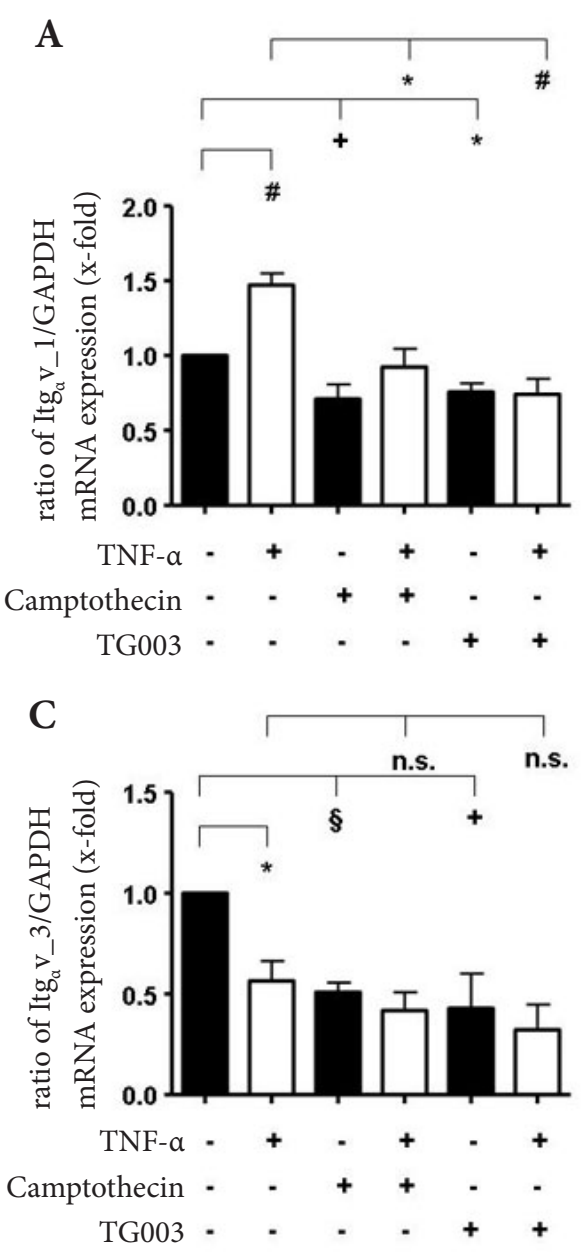

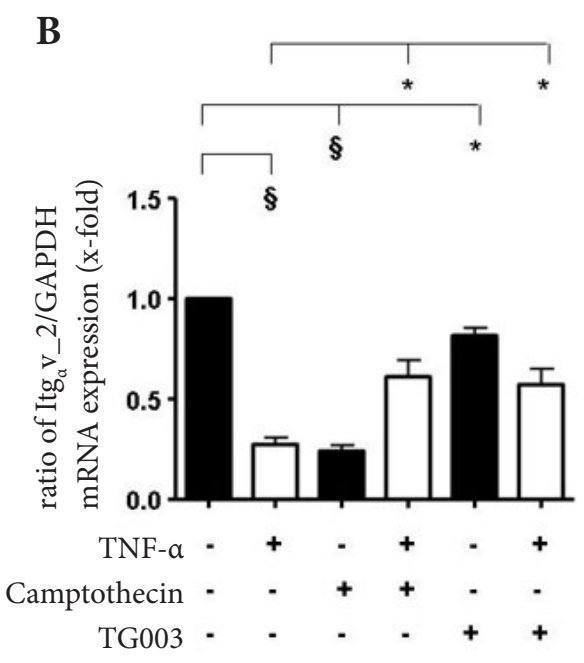

D

$$
\operatorname{anti}_{-} \operatorname{Itg}_{\alpha} \mathrm{v}_{-} 1(116 \mathrm{kD})
$$

anti-GAPDH (37 KD)

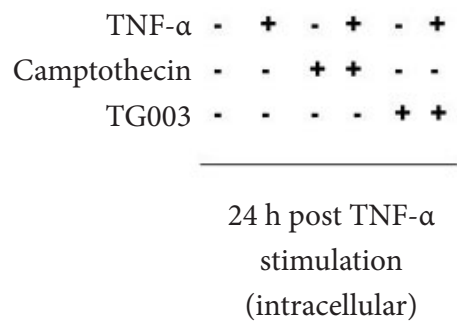

Figure 2. The impact of Clks and DNA topo I on the $\operatorname{Itg}_{\alpha} \mathrm{v}$ isoform expression. (A-C) Ratio of the (A) $\operatorname{Itg}_{\alpha} \mathrm{v}_{-} 1$, (B) $\operatorname{Itg}_{\alpha} \mathrm{v} \_2$, and (C) $\operatorname{Itg}_{\alpha} \mathrm{v} \_3$ mRNA expression normalized against GAPDH of $1 \times 10^{6} \mathrm{HMEC}-1$, $2 \mathrm{~h}$ post TNF- $\alpha$ treatment. (D) The expression of Itg $\mathrm{v}$ and GAPDH protein $24 \mathrm{~h}$ post TNF- $\alpha$-induction. Compared are non-treated control cells, TNF- $\alpha$-induced cells, and HMEC-1 pre-incubated with $10 \mu \mathrm{M}$ TG003 or $100 \mathrm{nM}$ camptothecin, respectively, with or without TNF- $\alpha$. The mean \pm SEM of at least 3 independent experiments is shown. $(+) \mathrm{p}<0.05$; $\left(^{*}\right) \mathrm{p}<0.01$; (\#) $\mathrm{p}<0.001 ;(\S) \mathrm{p}<0.0001$; (n.s.) no significant difference.

influence of SR protein kinase inhibition under normal as well as under inflammatory conditions. On mRNA level, the predominantly expressed $\operatorname{ltg}_{a} v$ isoform, $\operatorname{Itg}_{a} v_{-} 1$ was significantly increased by TNF-a stimulation of HMEC- 1 for $2 \mathrm{~h}$ (Figure $\mathbf{2 A}$ ). Inhibition of DNA topo I or Clks significantly reduced the $\operatorname{Itg}_{a} v_{-} 1$ expression in non-stimulated as well as in TNF-a-induced cells. In contrast to $\operatorname{ltg}_{a} v_{-} 1$, the mRNA expression of the $\operatorname{Itg}_{\alpha} \mathrm{v} \_2$ splice variant was significantly reduced in TNF-a-stimulated cells (Figure 2B). The level of Itg $\mathrm{t}_{\mathrm{a}} \_2$ in HMEC-1 was reduced by inhibition of DNA topo $\mathrm{I}$ and $\mathrm{Clks}$. In contrast to resting cells, the expression of this splice variant was significantly increased by pre-treatment with camptothecin or TG003, respectively, in TNF-a-induced cells (Figure 2B). The expression of the third mRNA splice variant, $\operatorname{ltg}_{a} v_{-} 3$ was also reduced in cells stimulated for $2 \mathrm{~h}$ with TNF-a, compared to non-stimulated controls (Figure 2C).
Inhibition of DNA topo I or Clks significantly decreased the expression of $\operatorname{Itg}_{a} v_{-} 3$ in resting HMEC-1. In contrast to non-stimulated cells, blocking of DNA topo I and Clks had no significant influence on $\operatorname{Itg}_{a} v_{-} 3$ mRNA in TNF-a-induced cells (Figure $2 \mathrm{C}$ ). The protein expression of $\operatorname{Itg}_{a} v_{-} 1$ was also modulated (Figure 2D). Stimulation of HMEC-1 for $24 \mathrm{~h}$ with TNF- $a$ induced the protein expression of $\mathrm{Itg}_{a} \mathrm{~V} \_$1. Pre-treatment of cells with the DNA topo I inhibitor significantly reduced the expression of $\mid \operatorname{tg}_{a} v_{-} 1$ in resting as well as in stimulated cells. In contrast, the inhibition of Clks had no influence on the protein expression of $\operatorname{Itg}_{a} v_{-} 1$, compared to non-stimulated or TNF-a-induced HMEC-1, respectively (Figure 2D).

The modulation of endothelial cell functions by Clks and DNA topo I

Since Cyr61 and the receptor $\operatorname{Itg}_{a} v$ are involved in the 


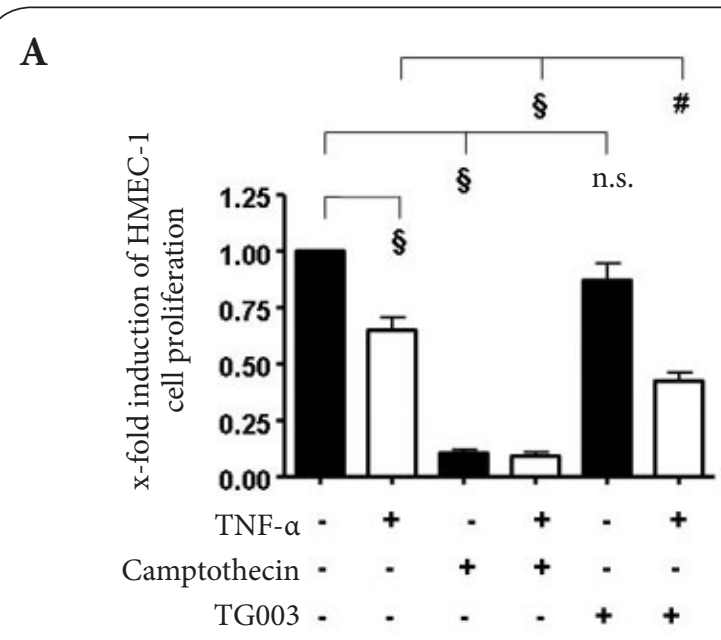

B

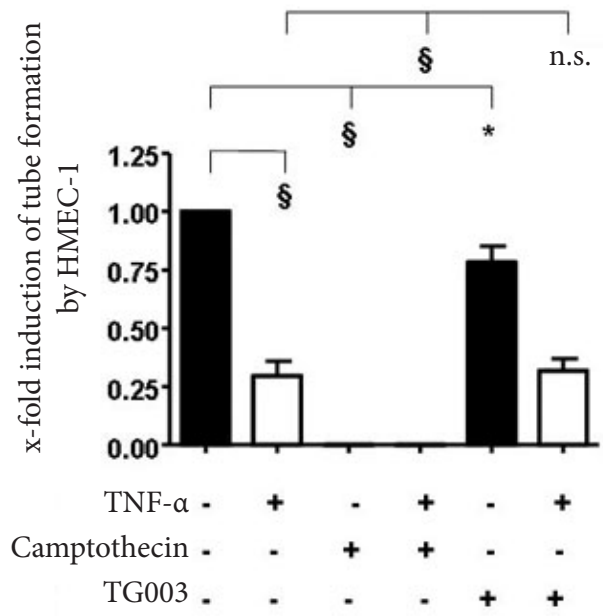

Figure 3. The influence of Clks and DNA topo I on cellular functions of HMEC-1.

(A) MTT cell proliferation assay in HMEC-1 $48 \mathrm{~h}$ post TNF- $\alpha$ stimulation. (B) Tube formation assay in HMEC$15 \mathrm{~h}$ post TNF- $\alpha$ treatment. Shown are non-treated controls, TNF- $\alpha$-stimulated HMEC-1, and cells preincubated with $10 \mu \mathrm{M}$ TG003 or $100 \mathrm{nM}$ camptothecin, respectively, with or without TNF- $\alpha$. The mean \pm SEM of at least 3 independent experiments is shown. $(+)$ $\mathrm{p}<0.05 ;\left(^{*}\right) \mathrm{p}<0.01$; (\#) $\mathrm{p}<0.001 ;(\S) \mathrm{p}<0.0001$; (n.s.) no significant difference.

modulation of endothelial cell functions, such as cell proliferation and angiogenesis, we characterized the impact of DNA topo I inhibition as well as of Clk blocking on endothelial cell number and on pro-angiogenic tube formation by HMEC-1. Treatment of cells with $10 \mathrm{ng} / \mathrm{mL}$ TNF-a significantly reduced the cell proliferation of these cells $48 \mathrm{~h}$ post stimulation (Figure 3A). Pre-treatment of cells with the DNA topo I inhibitor camptothecin significantly reduced the cell proliferation in nonstimulated as well as in TNF-a-induced HMEC-1. Clk inhibition by TG003 had no impact on the cell number in resting cells, whereas, the cell proliferation was decreased in TNF-a-treated cells compared to the corresponding controls (Figure 3A).
The endothelial tube formation was significantly decreased by stimulation of HMEC-1 for $5 \mathrm{~h}$ with TNF-a (Figure 3B). Inhibition of DNA topo I by camptothecin nearly completely abolished the endothelial tube formation in resting as well as in TNF-a-induced cells. Inhibition of Clks by TG003 slightly reduced the tube formation in resting cells, whereas, it had no further influence in TNF-a-treated HMEC-1 compared to controls (Figure 3B).

The impact of Cyr61 on cell proliferation and tube formation of HMEC-1

To test whether the cell proliferation may be modulated by SR protein kinase-mediated regulation of the isoform expression of Cyr61, we analysed the effect of recombinant (r)Cyr61_IS protein as well as of isoform-specific siRNAs against Cyr61_IS or Cyr61_IR, respectively. Treatment of HMEC-1 with rCyr61_IS significantly induced cell proliferation (Figure 4A). Since no rCyr61_IR is available, we tested the influence of isoformspecific inhibitory siRNAs against Cyr61_IS or Cyr61_IR on endothelial cell proliferation (Figure 4B). Transfection of HMEC-1 with siRNAs against the protein-coding Cyr61_IS splice variant significantly decreased the cell proliferation after $24 \mathrm{~h}$. In contrast, treatment of HMEC-1 with siRNAs against the non-coding Cyr61_IR mRNA variant increased the cell proliferation (Figure 4B).

Stimulation with rCyr61_IS significantly increased the tube formation by HMEC-1 after $5 \mathrm{~h}$ (Figure 4C). In turn, inhibition of protein-coding Cyr61_IS by siRNAs reduced the endothelial tube formation (Figure 4D). SiRNA-mediated silencing of Cyr61_IR also decreased the pro-angiogenic tube formation by HMEC-1 (Figure 4D).

\section{Discussion}

Regulation of the isoform expression of Cyr61 and $\operatorname{Itg}_{a} v$ in endothelial cells

Alternative splicing processes play an important role in the patho-physiology of human diseases as well as in the regulation of vascular functions [3,16-18]. The SR protein kinases Clks and DNA topo I regulate post-transcriptional spicing of primary transcripts [10-12].

In this study, we showed both kinases to be involved in the differential isoform expression of Cyr61 and its receptor I $_{a} v$ in endothelial cells under resting as well as under inflammatory conditions. Hirschfeld et al., found pathophysiologic stimuli, such as hypoxia to modulate the isoform expression of Cyr61 in cancer [8]. We demonstrated stimulation of endothelial cells with the pro-inflammatory cytokine TNF-a to modulate the isoform expression pattern of Cyr61_IS and Cyr61_IR in opposite ways. Treatment of HMEC-1 with TNF-a increased Cyr61_IS and decreased the level of Cyr61_IR mRNA. This is in line with the data of other groups showing the expression of the functional Cyr61_IS isoform to be elevated under inflammatory conditions $[7,19]$. Analogously to the Cyr61 isoform pattern, the expression of the protein-coding $\operatorname{ltg}_{a} v_{-} 1$ 
A

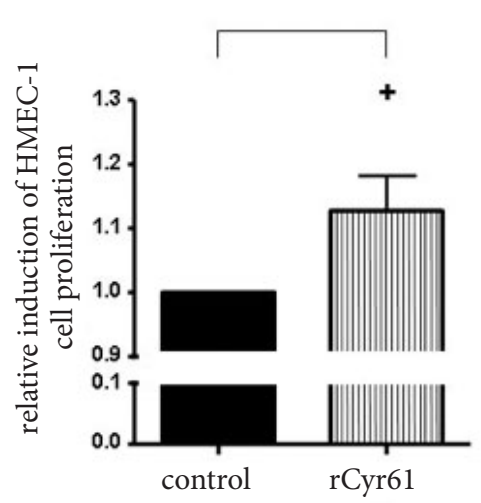

C

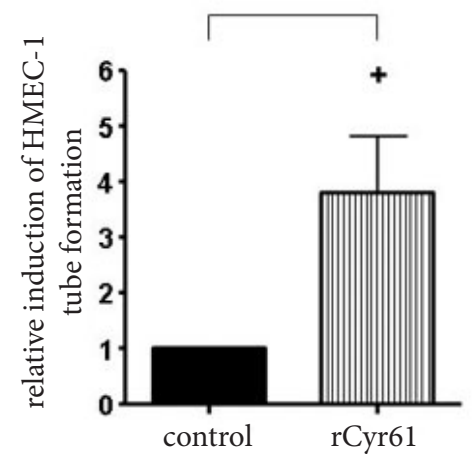

B

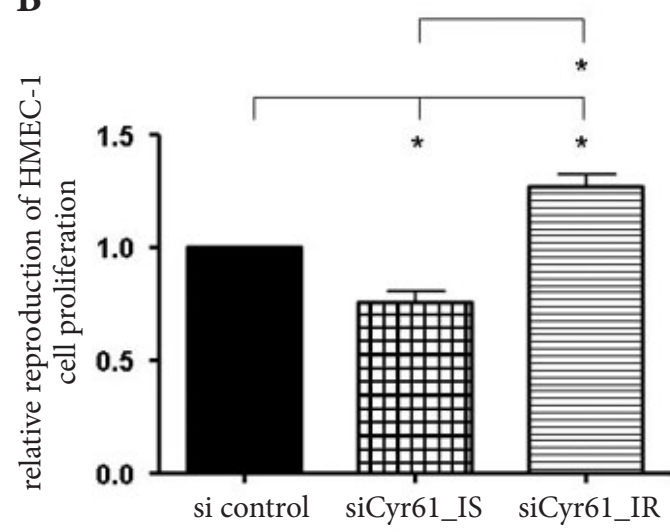

D

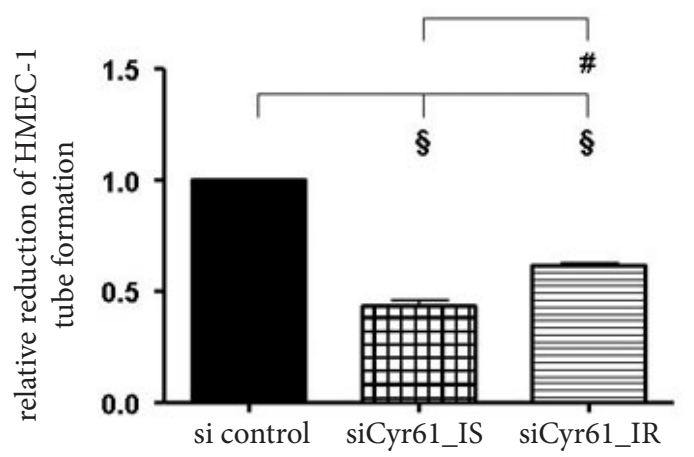

Figure 4. The pro-angiogenic effect of Cyr61 in HMEC-1.

(A, B) MTT proliferation assay of endothelial cells treated with (A) rCyr61 protein for $5 \mathrm{~h}$ or (B) transfected for 48h with specific siRNAs against Cyr61_IS (siCyr61_IS) or Cyr61_IR (siCyr61_IR), respectively. In (A) non-treated cells in (B) cells transfected with a non-sense siRNA (si control) were used as controls. (C, D) Tube formation assay of HMEC-1 treated with (A) rCyr61 protein for $5 \mathrm{~h}$ or (B) transfected for 48h with specific siRNAs against Cyr61_IS (siCyr61_IS) or Cyr61_IR (siCyr61_ IR), respectively. In (A) non-treated cells in (B) cells transfected with a non-sense siRNA (si control) were used as controls. The mean \pm SEM of at least 3 independent experiments is shown. $(+) \mathrm{p}<0.05$; $\left.{ }^{*}\right) \mathrm{p}<0.01 ;(\#) \mathrm{p}<0.001 ;(\S) \mathrm{p}<0.0001$.

was increased, whereas, the mRNA level of $\operatorname{Itg}_{a} v_{-} 2$ and 3 was decreased under inflammatory conditions.

In our experiments, treatment of endothelial cells with pharmacologic inhibitors of Clks or DNA topo I, respectively, differentially modulated the expression pattern of $\operatorname{ltg}_{\alpha} v$ and Cyr61 mRNA splice variants. This is in line with earlier data, showing inhibition of these kinases to control the endothelial isoform expression of the cardiovascular-relevant mediators Tissue Factor (TF) and the endothelial nitric oxide synthase (eNOS) in differential ways $[\mathbf{1 1}, 13]$. The increase of one isoform was associated with a reduced expression of the other splice variant. This in turn regulated the protein expression profile. For example, the induction of functional protein-coding Cyr61_IS mRNA and reduction of the non-coding Cyr61_IR splice variant resulted consequently in an increased protein expression and secretion of Cyr61_IS. This effect was shown for the Cyr61 and the $\operatorname{ltg}_{a} v$ isoform expression pattern in resting as well as in TNF-a-stimulated HMEC-1. This is in line with the data of other groups, which showed that such antipodal modulation of the mRNA isoform expression is a common mechanism to regulate the protein expression [11,20-22].

Clks and DNA topo I were known to regulate splicing processes $[10,14]$. Regulation of pre-mRNA splicing was shown to modulate the isoform expression and cellular functions in the cardiovascular system $[\mathbf{1 1}, \mathbf{1 5}, \mathbf{2 3 - 2 6}]$.

\section{The functional impact of DNA topo I on HMEC-1}

As mentioned before, modulation of the isoform expression on post-transcriptional level can modulate cardiovascular functions, such as nitric oxide signaling or cellular thrombogenicity or cholesterol transport $[11,13,17]$. In our study, we found inhibition of the SR protein kinases DNA topo 
I or Clks, respectively, do differentially affect endothelial cell proliferation and pro-angiogenic tube formation.

Inhibition of DNA topo I led to a reduced cell proliferation rate and to a nearly completely abolished tube formation activity in resting as well as in pro-inflammatory-induced HMEC-1. This functional inhibition by the DNA topo I inhibitor was associated with a reduced expression and secretion of the migration-facilitating and pro-angiogenic Cyr61_IS isoform. Recently, inhibition of the SR protein kinase DNA topo I was demonstrated to modulate the isoform expression of TF, which in turn directly affected TF isoform-associated cellular functions, such as the procoagulant activity of endothelial cells [13]. In line with this, Solier et al., also found that blocking of DNA topo I lead to an altered isoform expression of caspase 2 and the caspase-2-mediated cellular apoptosis in cancer cells [27]. Therefore, we suggest that the inhibitory effect of DNA topo I blocking was -at least in part- mediated via reducing the expression of the Cyr61_IS isoform in these cells. This suggestion was substantiated by the results obtained from stimulation with rCyr61_IS as well as from inhibition experiments using specific siRNAs. Stimulation of HMEC-1 with rCyr61_IS protein increased their cell proliferation rate as well as the tube formation. In turn, siRNA-mediated silencing of Cyr61_IS reduced both, cell proliferation and tube formation. Thus, inhibition of Cyr61_IS protein on post-transcriptional level by blocking DNA topo I may subsequently lead to a reduced proliferation rate and tube formation by HMEC- 1 . Reduction of the Cyr61_IR splice variant by siRNA also reduced the endothelial tube formation, but slightly increased the cell proliferation. Since there is no protein expressed from this mRNA splice variant [8], we were not able to check a possible effect of functional proteins. But a possible explanation for this effect may be that the disproportionally increased ratio of Cyr61_IR mRNA vs. Cyr61_IS may lead to a capacity overload of the translation apparatus. This in turn may lead to the differential effects mentioned above.

Inhibition of Clks by TG003 in resting HMEC-1 had no impact on cell proliferation, but significantly reduced the pro-angiogenic tube formation by HMEC-1.

\section{The effect of Clk inhibition on cellular functions of endothelial cells}

The influence of Clk inhibition on cell proliferation and tube formation of HMEC-1 was very complex in HMEC-1. In resting cells, Clk inhibition had no influence on cell proliferation, but reduced the tube formation by HMEC-1. In TNF-a-stimulated cells, blocking of Clks by TG003 reduced the cell proliferation, but had no effect on endothelial tube formation. In this context, we found that the impact of $\mathrm{Clk}$ inhibition by TG003 reduced the mRNA expression of both Cyr61 splice variants, whereas, this had no significant effect in TNF-a-treated cells. Surprisingly, Inhibition of Clks had no impact on the protein expression level of Cyr61. However, the protein secretion was reduced by TG003 treatment in both, resting and TNF-a-induced
HMEC-1. Modulation of alternative splicing was shown to alter the secretion of protein isoforms [28-30]. This in turn modified cellular functions in different experimental settings [28-30]. Therefore, we assume that the pharmacologic Clk inhibition may affect the Cyr61_IS-mediated pro-angiogenic and proliferation-facilitating functions possibly via altering the secretion of this protein isoform.

In conclusion, this study points to DNA topo I and Clks to be - at least in parts - involved in the differential isoform expression of Cyr61 and $\operatorname{ltg}_{a} v$ by regulation of post-transcriptional splicing in resting as well as in TNF-a-induced human microvascular endothelial cells. Both proteins were known to play an essential role in vascular diseases as well as in endothelial regeneration $[4,7,31,32]$. Our findings indicate that post-transcriptional modulation of the differential isoform expression of Cyr61 may be involved in the regulation of important regenerative endothelial functions, such as cell proliferation and angiogenesis. Therefore, influencing the isoform expression of pro-angiogenic and proliferationfacilitating factors, such as Cyr61 may be of interest with regard to the development of new strategies for the treatment of vascular diseases. In this context, the specific role of the different isoform of Cyr61 as well as of $\operatorname{Itg}_{a} v$ in regulation of endothelial functions under (patho-)physiologic conditions should be characterized in detail and mechanistically analysed in further studies in the future.

\section{Competing interests}

The author's declare that they have no competing interests.

\section{Authors' contributions}

S. Gauck performed the study together with Dr. Eisenreich who planned the study. Professor Schultheiss and professor Rauch were involved in planning the study and preparation of the manuscript.

\section{Acknowledgement and funding}

This work was supported by grants from the Deutsche Forschungsgemeinschaft (GRK 865; SFB-TR19). We thank Dr. U. Leppert for supporting the manuscript preparation.

\section{Publication history}

EIC: William Clifford Roberts, Baylor University Medical Center, USA. Received: 01-Mar-2013 Revised: 12-Jul-2013

Accepted: 16-Jul-2013 Published: 26-Jul-2013

\section{References}

1. Ando J and Yamamoto K. Vascular mechanobiology: endothelial cell responses to fluid shear stress. Circ J. 2009; 73:1983-92. | Article | PubMed

2. Mochizuki N. Vascular integrity mediated by vascular endothelial cadherin and regulated by sphingosine 1-phosphate and angiopoietin-1. Circ J. 2009; 73:2183-91. | Article | PubMed

3. Eisenreich $A$ and Rauch $U$. Regulation and differential role of the tissue factor isoforms in cardiovascular biology. Trends Cardiovasc Med. 2010; 20:199-203. | Article | PubMed

4. Eisenreich A, Boltzen U, Malz R, Schultheiss HP and Rauch U. Overexpression of alternatively spliced tissue factor induces the proangiogenic properties of murine cardiomyocytic HL-1 cells. Circ J. 2011; 75:1235-42. | Article | PubMed 
Gauck et al. Cardiovascular System 2013,

http://www.hoajonline.com/journals/pdf/2052-4358-1-8.pdf

doi: $10.7243 / 2052-4358-1-8$

5. Kawamura A, Miura S, Murayama T, Iwata A, Zhang B, Nishikawa H, Tsuchiya Y, Matsuo K, Tsuji E and Saku K. Increased expression of monocyte CD11a and intracellular adhesion molecule-1 in patients with initial atherosclerotic coronary stenosis. Circ J. 2004; 68:6-10. | Article I PubMed

6. Leu SJ, Lam SC and Lau LF. Pro-angiogenic activities of CYR61 (CCN1) mediated through integrins alphavbeta 3 and alpha6beta 1 in human umbilical vein endothelial cells. J Biol Chem. 2002; 277:46248-55. I Article | PubMed

7. Löbel M, Bauer S, Meisel C, Eisenreich A, Kudernatsch R, Tank J, Rauch U, Kuhl U, Schultheiss HP, Volk HD, Poller W and Scheibenbogen C. CCN1: a novel inflammation-regulated biphasic immune cell migration modulator. Cell Mol Life Sci. 2012; 69:3101-13. | Article | PubMed

8. Hirschfeld M, zur Hausen A, Bettendorf $H$, Jager $M$ and Stickeler E. Alternative splicing of Cyr61 is regulated by hypoxia and significantly changed in breast cancer. Cancer Res. 2009; 69:2082-90. | Article | $\underline{\text { PubMed }}$

9. Monnier Y, Farmer P, Bieler G, Imaizumi N, Sengstag T, Alghisi GC, Stehle JC, Ciarloni L, Andrejevic-Blant S, Moeckli R, Mirimanoff RO, Goodman SL, Delorenzi M and Ruegg C. CYR61 and alphaVbeta5 integrin cooperate to promote invasion and metastasis of tumors growing in preirradiated stroma. Cancer Res. 2008; 68:7323-31. | Article | PubMed

10. Stamm S. Regulation of alternative splicing by reversible protein phosphorylation. J Biol Chem. 2008; 283:1223-7. I Article I PubMed

11. Eisenreich A, Boltzen U, Poller W, Schultheiss HP and Rauch U. Effects of the Cdc2-like kinase-family and DNA topoisomerase I on the alternative splicing of eNOS in TNF-alpha-stimulated human endothelial cells. Biol Chem. 2008; 389:1333-8. | Article I PubMed

12. Soret J, Gabut M, Dupon C, Kohlhagen G, Stevenin J, Pommier Y and Tazi J. Altered serine/arginine-rich protein phosphorylation and exonic enhancer-dependent splicing in Mammalian cells lacking topoisomerase I. Cancer Res. 2003; 63:8203-11. I Article I PubMed

13. Eisenreich A, Bogdanov VY, Zakrzewicz A, Pries A, Antoniak S, Poller W, Schultheiss HP and Rauch U. Cdc2-like kinases and DNA topoisomerase I regulate alternative splicing of tissue factor in human endothelial cells. Circ Res. 2009; 104:589-99. | Article | PubMed

14. Debdab M, Carreaux F, Renault S, Soundararajan M, Fedorov O, Filippakopoulos P, Lozach O, Babault L, Tahtouh T, Baratte B, Ogawa Y, Hagiwara M, Eisenreich A, Rauch U, Knapp S, Meijer L and Bazureau JP. Leucettines, a class of potent inhibitors of cdc2-like kinases and dual specificity, tyrosine phosphorylation regulated kinases derived from the marine sponge leucettamine B: modulation of alternative pre-RNA splicing. J Med Chem. 2011; 54:4172-86. | Article | PubMed

15. Eisenreich A, Malz R, Pepke W, Ayral Y, Poller W, Schultheiss HP and Rauch U. Role of the phosphatidylinositol 3-kinase/protein kinase B pathway in regulating alternative splicing of tissue factor mRNA in human endothelial cells. Circ J. 2009; 73:1746-52. | Article | PubMed

16. Hiura Y, Tabara Y, Kokubo Y, Okamura T, Goto Y, Nonogi H, Miki T, Tomoike $\mathrm{H}$ and Iwai $\mathrm{N}$. Association of the functional variant in the 3-hydroxy3-methylglutaryl-coenzyme a reductase gene with low-density lipoprotein-cholesterol in Japanese. Circ J. 2010; 74:518-22. | Article | PubMed

17. Nagano M, Nakamura M, Kobayashi N, Kamata J and Hiramori K. Effort angina in a middle-aged woman with abnormally high levels of serum high-density lipoprotein cholesterol: a case of cholesteryl-ester transfer protein deficiency. Circ J. 2005; 69:609-12. | Article | PubMed

18. Watanabe A, Kosho T, Wada T, Sakai N, Fujimoto M, Fukushima Y and Shimada T. Genetic aspects of the vascular type of Ehlers-Danlos syndrome (vEDS, EDSIV) in Japan. Circ J. 2007; 71:261-5. | Article | PubMed

19. Koziol A, Gonzalo P, Mota A, Pollan A, Lorenzo C, Colome N, Montane D, Dopazo J, Arribas J, Canals F and Arroyo AG. The protease MT1-MMP drives a combinatorial proteolytic program in activated endothelial cells. FASEB J. 2012; 26:4481-94. | Article | PubMed

20. Mercatante DR, Bortner CD, Cidlowski JA and Kole R. Modification of alternative splicing of Bcl-x pre-mRNA in prostate and breast cancer cells. analysis of apoptosis and cell death. J Biol Chem. 2001; 276:164117. | Article | PubMed
21. Boltzen U, Eisenreich A, Antoniak S, Weithaeuser A, Fechner H, Poller W, Schultheiss HP, Mackman N and Rauch U. Alternatively spliced tissue factor and full-length tissue factor protect cardiomyocytes against TNFalpha-induced apoptosis. J Mol Cell Cardiol. 2012; 52:1056-65. I Article | PubMed

22. Leppert U, Henke W, Huang X, Muller JM and Dubiel W. Posttranscriptional fine-tuning of COP9 signalosome subunit biosynthesis is regulated by the c-Myc/Lin28B/let-7 pathway. J Mol Biol. 2011; 409:710-21. | Article | PubMed

23. Tardos JG, Eisenreich A, Deikus G, Bechhofer DH, Chandradas S, Zafar U, Rauch U and Bogdanov VY. SR proteins ASF/SF2 and SRp55 participate in tissue factor biosynthesis in human monocytic cells. J Thromb Haemost. 2008; 6:877-84. | Article | PubMed

24. Eisenreich A, Celebi O, Goldin-Lang P, Schultheiss HP and Rauch U. Upregulation of tissue factor expression and thrombogenic activity in human aortic smooth muscle cells by irradiation, rapamycin and paclitaxel. Int Immunopharmacol. 2008; 8:307-11. | Article I PubMed

25. Takemura H, Yasui K, Opthof T, Niwa N, Horiba M, Shimizu A, Lee JK, Honjo H, Kamiya K, Ueda Y and Kodama I. Subtype switching of L-Type Ca 2+ channel from Cav1.3 to Cav1.2 in embryonic murine ventricle. Circ J. 2005; 69:1405-11. | Article | PubMed

26. Eisenreich A and Rauch U. PI3K inhibitors in cardiovascular disease. Cardiovasc Ther. 2011; 29:29-36. | Article | PubMed

27. Solier S, Lansiaux A, Logette E, Wu J, Soret J, Tazi J, Bailly C, Desoche L, Solary E and Corcos L. Topoisomerase I and II inhibitors control caspase-2 pre-messenger RNA splicing in human cells. Mol Cancer Res. 2004; 2:53-61. | Article | PubMed

28. Furuya T, Koga M, Hikami K, Kawasaki A and Tsuchiya N. Effects of APRIL (TNFSF13) polymorphisms and splicing isoforms on the secretion of soluble APRIL. Mod Rheumatol. 2012; 22:541-9. | Article | PubMed

29. Wang Y, Geng Z, Zhao L, Huang SH, Sheng AL and Chen ZY. GDNF isoform affects intracellular trafficking and secretion of GDNF in neuronal cells. Brain Res. 2008; 1226:1-7. | Article | PubMed

30. Schwarzbauer JE. Alternative splicing of fibronectin: three variants, three functions. Bioessays. 1991; 13:527-33. | Article I PubMed

31. You JJ, Yang CH, Chen MS and Yang CM. Cysteine-rich 61, a member of the CCN family, as a factor involved in the pathogenesis of proliferative diabetic retinopathy. Invest Ophthalmol Vis Sci. 2009; 50:3447-55. | Article I PubMed

32. Estrada R, Li N, Sarojini H, An J, Lee MJ and Wang E. Secretome from mesenchymal stem cells induces angiogenesis via Cyr61. J Cell Physiol. 2009; 219:563-71. | Article | PubMed Abstract | PubMed Full Text

33. Muraki M, Ohkawara B, Hosoya T, Onogi H, Koizumi J, Koizumi T, Sumi K, Yomoda J, Murray MV, Kimura H, Furuichi K, Shibuya H, Krainer AR, Suzuki $\mathrm{M}$ and Hagiwara $\mathrm{M}$. Manipulation of alternative splicing by a newly developed inhibitor of Clks. J Biol Chem. 2004; 279:24246-54. | Article I PubMed

34. Rossi F, Labourier E, Forne T, Divita G, Derancourt J, Riou JF, Antoine E, Cathala G, Brunel C and Tazi J. Specific phosphorylation of SR proteins by mammalian DNA topoisomerase I. Nature. 1996; 381:80-2. | Article I PubMed

\section{Citation:}

Gauck S, Schultheiss H-P, Rauch U and Eisenreich A. Modulation of the isoform expression of Cyr61 and Integrin- $\alpha v$ in human microvascular endothelial cells. Cardio Vasc Syst. 2013; 1:8. http://dx.doi.org/10.7243/2052-4358-1-8 